\title{
Oat Allergy: Report on 2 Cases
}

Tomás-Pérez $\mathrm{M}^{1}$, Iglesias-Souto $\mathrm{FJ}^{2}$, Bartolome $\mathrm{B}^{3}$

${ }^{1}$ Department of Allergy, Hospital La Paz, Madrid, Spain

${ }^{2}$ Department of Allergy, Hospital Nuestra Señora de la Candelaria, Santa Cruz de Tenerife, Spain

${ }^{3}$ Roxall, R\&D Department, Bilbao, Spain

J Investig Allergol Clin Immunol 2020; Vol. 30(3): 199-201 doi: $10.18176 /$ jiaci.0477

Key words: Oat allergy. Cereal allergy.

Palabras clave: Alergia a avena. Alergia a cereales.

Oat (Avena sativa) is a cereal from the Poaceae family that has become very popular in our setting due to its high nutritional value. All varieties of oats contain gluten and avenin, which is a prolamin similar to wheat gliadin. Oats are used as animal feed or as food in our diet, whether in grain, flour, or oat drinks. Despite the widespread consumption of this cereal, few cases of oat allergy have been described.

We report 2 cases of anaphylaxis to oat in patients who tolerated other cereals.

The first patient was 14-year-old boy with a personal history of atopic dermatitis and recurrent croup. He consulted because he presented pruritus (pharynx, hands, and feet) and facial erythema with no other symptoms immediately after the ingestion of oat milk. The reaction resolved with antihistamines and corticosteroids in the emergency department. He had previously presented with oral pruritus after ingestion of oats. He tolerates wheat and other cereals.

Skin prick test (SPT) with the most common aeroallergens (dust mites, pollens, molds, pet dander) yielded a negative result. SPT to oat extract was positive $(6 \times 6 \mathrm{~mm})$. Total $\mathrm{IgE}$ of $80 \mathrm{IU} / \mathrm{mL}$, and specific IgE (CAP), in $\mathrm{kU}_{\mathrm{A}} / \mathrm{L}$, was as follows: oat, 6.79; wheat, 0.38 ; rye, barley, corn, rice, Tri a 19, and Tri a $14,<0.35$

The second patient was a 62 -year-old man with a personal history of ischemic heart disease, who developed anaphylaxis to oat milk. Within 5 minutes of ingestion, he developed oropharyngeal pruritus, dysphonia, and dyspnea, followed by acute generalized urticaria, which resolved after treatment with epinephrine, corticosteroids, and antihistamines in the emergency department. The patient did not take nonsteroidal antiinflammatory drugs or exercise before ingestion, and no other cofactors or possible triggers of the adverse reaction were identified. He currently tolerates all other types of cereals, except oat.

SPT performed with the most common aeroallergens (dust mites, pollens, molds, pet dander) yielded negative results. SPT performed with cereal extracts yielded a positive result to oat $(10 \times 9 \mathrm{~mm})$, maize $(10 \times 10 \mathrm{~mm})$, wheat $(7 \times 6 \mathrm{~mm})$, rice $(5 \times 5 \mathrm{~mm})$, and barley $(6 \times 5 \mathrm{~mm})$. Total $\mathrm{IgE}$ was $82.40 \mathrm{IU} / \mathrm{mL}$, and specific $\operatorname{IgE}(\mathrm{CAP})$, in $\mathrm{kU}_{\mathrm{A}} / \mathrm{L}$, was as follows: oat, 40.10; wheat, 1.68; maize, 1.61; barley, 2.70; and rye, 2.04. 


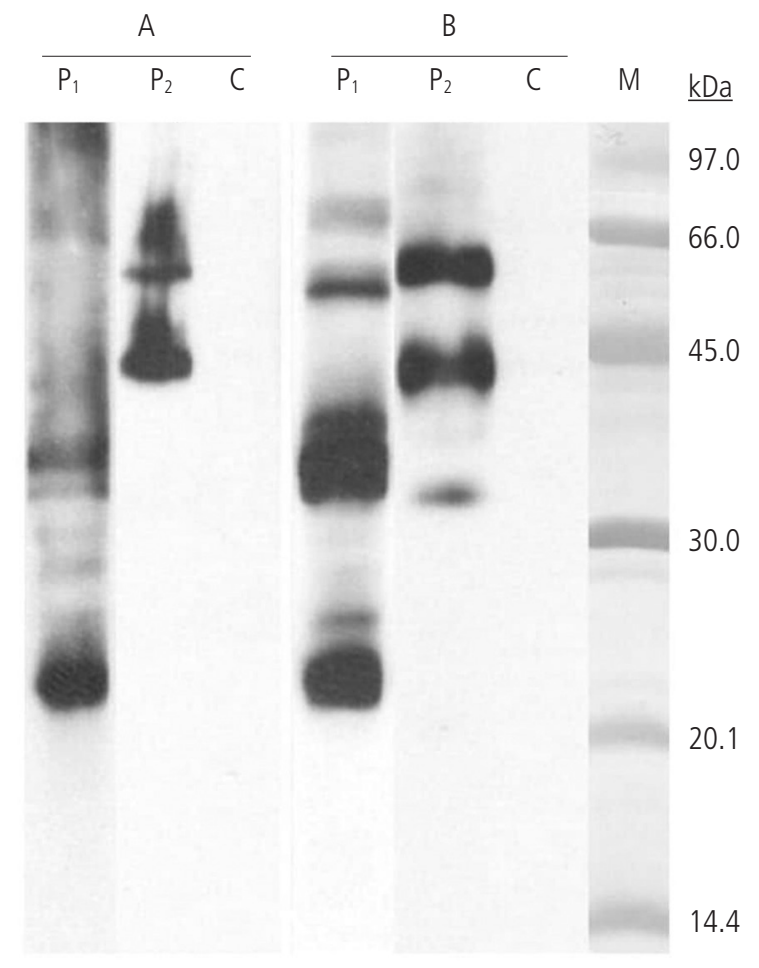

Figure. SDS-PAGE immunoblotting. A, Oat milk extract. B, Oat seed extract. Lane $P_{1}$, Patient sera $1 ; P_{2}$, Patient sera 2 ; Lane $C$, Control serum (pool of sera from nonatopic subjects); Lane M, Molecular mass standard.

Protein extracts from oat milk and oat seed were prepared by homogenization in phosphate-buffered saline, dialyzation, and lyophilization. SDS-PAGE immunoblotting was carried out according to Laemmli under reducing conditions (with mercaptoethanol) with oat seed and oat milk extracts and sera from both patients. Serum from the first patient revealed IgE-binding bands of $34-35 \mathrm{kDa}$, $29.5 \mathrm{kDa}, 28 \mathrm{kDa}$, and $22.5 \mathrm{kDa}$ in oat milk extract and bands of $70 \mathrm{kDa}, 50 \mathrm{kDa}, 34-35 \mathrm{kDa}, 26 \mathrm{kDa}$, and $22.5 \mathrm{kDa}$ in oat seed extract. Analysis of serum from patient 2 revealed IgE-reactive bands of $55 \mathrm{kDa}$ and $42 \mathrm{kDa}$ in both oat extracts, as well as a faint $33-\mathrm{kDa}$ band in oat seed extract.

We report 2 cases of allergy (anaphylaxis) due to ingestion of oat milk, one in an adult and the other in a child. In both cases, we demonstrated an IgE-mediated mechanism. Both patients were sensitized to wheat, and one (patient 2) was also sensitized to other cereals (rice, maize, and barley). Both patients tolerated all other types of cereal except oats. Regarding the identity of the IgE-binding proteins detected in the immunoblotting analysis, the $34-35-\mathrm{kDa}$ band could correspond to an oat protein that is homologous to the wheat allergen Tri a 20 (molecular weight, $35-38 \mathrm{kDa}$ ), thus accounting for the slight sensitization to wheat in the first patient. The $22.5-\mathrm{kDa}$ band could be a $12 \mathrm{~S}$ oat seed globulin, and the band of around $50 \mathrm{kDa}$ would correspond to a $48-\mathrm{kDa}$ oat serpin previously described as an oat allergen in milk oat [1-3]. Only 3 bands were detected in the serum of the second patient $(55,42$, and $33 \mathrm{kDa})$.

We found a further 3 cases of allergy to oats [4-6]. Inuo et al [4] described a case of anaphylaxis in a child with a positive SPT result against oat and wheat (although the patient tolerated wheat). This case resembles the first patient we report, where the molecular weights of the potential allergens were around $23 \mathrm{kDa}, 30 \mathrm{kDa}$, and $35 \mathrm{kDa}$, the first of which could correspond to $12 \mathrm{~S}$ seed storage proteins, as mentioned above. The second case we report could correspond to the $33-\mathrm{kDa}$ protein identified. Prados-Castaño et al [3] reported a 48-kDa serpin from oat seed, which was identified using proteomic technology as the probable cause of an anaphylactic reaction after ingestion of oat milk. In the cases we report, we observed a band of around $45 \mathrm{kDa}$ (42 $\mathrm{kDa})$, which could correspond to this previously described serpin. Finally, Ototake et al [6] described a case of anaphylaxis induced by ingestion of oats with similar results in IgE-immunoblotting. The authors detected bands at approximately $25,30,33$, and $45 \mathrm{kDa}$, as in the case of Inuo et al. In the cases we report, we detected bands of around 22.5 and $34-35 \mathrm{kDa}$ in the first patient and bands of 42 and $33 \mathrm{kDa}$ in the second patient, which could correspond to those reported by Inuo et al.

Despite being sensitized to other types of cereals, the patients in the present report are able to tolerate them, possibly because cereals (wheat, oats, rye) have homologous prolamins and those of oat are less similar to each other [5].

We present 2 cases of allergy to oat with concomitant sensitization to other cereals that are well tolerated. We emphasize the importance of defining a specific sensitization profile in these patients in order to help us predict the importance of possible future allergic reactions.

\section{Funding}

The authors declare that no funding was received for the present study.

\section{Conflicts of Interest}

The authors declare that they have no conflicts of interest.

\section{References}

1. Sotkovsky P, Sklenar J, Halada P, Cinova J, Setinova I, Kainarova $A$, et al. A new approach to the isolation and characterization of wheat flour allergens. Clin Exp Allergy. 2011;41:1031-43.

2. Dupont FM, Vensel WH, Tanaka CK, Hurkman WJ, Altenbach SB. Deciphering the complexities of the wheat flour proteome using quantitative two-dimensional electrophoresis, three proteases and tandem mass spectrometry. Proteome Sci. 2011;9:10.

3. Prados-Castaño $M$, Piñero-Saavedra $M$, Leguisamo-Milla S, Pastor C, Cuesta P, Bartolomé B. Anaphylaxis Due to Oat Ingestion. J Investig Allergol Clin Immunol. 2016;26:68-9.

4. Inuo C, Kondo Y, Itagaki Y, Kurihara K, Tsuge I, Yoshikawa T, et al. Anaphylactic reaction to dietary oats. Ann Allergy Asthma Immunol. 2013;110:305-6. 
5. Tatham AS1, Shewry PR. Allergens to wheat and related cereals. Clin Exp Allergy. 2008;38:1712-26.

6. Ototake Y, Inomata N, Sano S, Takahashi S, Aihara M. A case of an anaphylactic reaction due to oats in granola. Allergol Int. 2015;64:386-7.

Manuscript received October 14, 2019; accepted for publication January 7, 2020.

Margarita Tomas Pérez

Department of Allergy Hospital La Paz

Paseo de la Castellana, 261

28046 Madrid, Spain

E-mail: margui.tomas@gmail.com 